\title{
IN VITRO STUDIES OF BIOMATERIAL DEVICE “HYDROXYAPATITE” PREPARED FROM DIFFERENT ROUTES FOR BIOMEDICAL APPLICATIONS
}

\author{
ISHFAQ RASOOL, ANJUVAN SINGH* \\ ${ }^{1}$ Department of Biotechnology, School of Bioengineering and Biosciences, Lovely Professional University (LPU), Phagwara - 144 411, \\ Punjab, India. Email: anjuvan@gmail.com
}

Received: 21 May 2018, Revised and Accepted: 25 August 2018

\section{ABSTRACT}

Objective: Biomaterial devices are used to replace any damaged or destroyed parts of the human body. Our body tissue and bone perform for an extended period of time, but sometimes they do suffer from a kind of destructive processes, including infection, fracture, or loss of function. The objective of our study is to solve the existing problem, as it may be possible to get rid of the diseased tissue and put back it with some suitable synthetic material.

Methods: A new versatile and economic method is used for the synthesis of hydroxyapatite (Hap). In this method, the effect of three different stirring techniques (ultrasonic, magnetic, and double-step stirring) on the properties of hydroxyapatite was investigated. Synthesis of hydroxyapatite by different methods was confirmed by Fourier transform-infrared (FT-IR), X-ray diffraction (XRD), and scanning electron microscopy analysis. An in vitro study of synthesized hydroxyapatite was done to test for biocompatibility.

Results: Pure white and crystalline hydroxyapatite was obtained by the chemical precipitation method as it was confirmed through XRD and FTIR analysis. It was confirmed that hydroxyapatite synthesized using sonication and magnetic stirring method was pure and stable in nature. The bioactivity evaluation of synthesized hydroxyapatite was done using biodegradation tests and by its interaction with the peripheral blood mononuclear cells.

Conclusion: Hydroxyapatite was synthesized successfully by bringing variation in process parameters using a chemical precipitation method. To prove for biocompatibility behavior of synthesized biomaterial bioactivity and biodegradation test was done successfully.

Keywords: Hydroxyapatite, Synthetic body fluid, Bioactivity, Biocompatibility.

(C) 2018 The Authors. Published by Innovare Academic Sciences Pvt Ltd. This is an open access article under the CC BY license (http://creativecommons. org/licenses/by/4. 0/) DOI: http://dx.doi.org/10.22159/ajpcr.2018.v11i10.27452

\section{INTRODUCTION}

Hydroxyapatite $\left[\mathrm{Ca}_{10}\left(\mathrm{PO}_{4}\right)_{6}(\mathrm{OH})_{2}, \mathrm{HAp}\right]$ has been employed to reconstruct bone defects due to its excellent biocompatibility, osteoconductivity, and close similarity to the human bone structure. Hydroxyapatite is a major constituent of bones and teeth which can be used as dental and medical research due to its excellent chemical and thermal stability, and good biocompatibility [1]. Nowadays, with an increase in accidental issues and demand of people metals of steel, titanium, cobalt-chrome, ceramics of hydroxyapatite, and calcium phosphate are currently used in cartilage, bone and joint replacement [2]. Apart from using as substitutes in our body other application of hydroxyapatite is to develop a composite porous biomaterial so that it can slowly release antibiotic as ciprofloxacin [3]. Several processes have been developed for the synthesis of hydroxyapatite, but the wet-chemical precipitation route is the best route for HAp synthesis, due to its great importance and wide utilization in dental and medical research. Hence, wet chemical reaction media involve no foreign elements except water, the only by-product [4]. Many factors (for example, starting materials, $\mathrm{pH}$, temperature, stirring speed, and aging time) influence the properties of hydroxyapatite. To get pure HAp, precise control of particle size and other parameters such as nature and composition of the starting materials, temperature of the solutions, $\mathrm{pH}$, stirring technique, and stirring speed must be controlled [5]. Hence, the different stirring methods were used to prevent the particle agglomeration and aggregation. Here, three different stirring techniques are used for hydroxyapatite synthesis magnetic, ultrasonic, and magnetic with ultrasonic stirring technique. Magnetic and ultrasonic stirring techniques were used to precipitate hydroxyapatite powder. The magnetic with ultrasonic technique includes magnetic stirring and ultrasonic irradiation techniques to synthesize hydroxyapatite. In this work, HAp powders were synthesized by three different routes using calcium nitrate and $\mathrm{KH}_{2} \mathrm{PO}_{4}$ as starting materials and the effects of different stirring techniques on the properties of HA powder were investigated by the techniques such as Fourier transform infrared (FTIR) and X-ray diffraction (XRD) [6].

\section{METHODS}

Hydroxyapatite was prepared using chemical precipitation by three different methods. Calcium nitrate $\left(\mathrm{Ca}\left[\mathrm{NO}_{3}\right]_{2} .4 \mathrm{H}_{2} \mathrm{O}\right)$ and potassium dihydrogen orthophosphate $\left(\mathrm{KH}_{2} \mathrm{PO}_{4}\right)$ were taken as starting materials in all the three synthesis processes. Sonication with magnetic stirring method was the most preferred method for the synthesis of hydroxyapatite as the only byproduct of this reaction was water and involves no foreign elements. $\mathrm{Ca}\left(\mathrm{NO}_{3}\right)_{2} 4 \mathrm{H}_{2} \mathrm{O}$ and $\mathrm{KH}_{2} \mathrm{PO}_{4}$ were weighed at molar ratios of $\mathrm{Ca} / \mathrm{P}=1.67$ and dissolved in distilled water to prepare a homogenous solution. The $\mathrm{pH}$ of as such prepared aqueous solution was controlled to 11 using $\mathrm{NH}_{4} \mathrm{OH}$ solution. The dropwise addition of $\mathrm{KH}_{2} \mathrm{PO}_{4}$ aqueous solution to calcium nitrate solution was vigorously stirred for about $1 \frac{1 / 2}{2}$ at $80^{\circ} \mathrm{C}$ temperature followed by aging for $22-24 \mathrm{~h}$. It was then washed 3 times and filtered in a filter glass. After completing the washing process, centrifugation of the solution occurs at 1500$2000 \mathrm{rpm}$ for $10 \mathrm{~min}$ produced a milky gelatinous precipitate. Then, the milky gelatinous precipitate is dried at $100^{\circ} \mathrm{C}$ for $4 \mathrm{~h}$. The dried powders of Hap were crushed to fine powder using mortar and pestle and calcined at $800^{\circ} \mathrm{C}$ to increase the crystallinity of the hydroxyapatite material. After completing the calcination process, hydroxyapatite pallets were formed by the tablet punching machine. It is a mechanical device that compresses the powder into pallets of uniform size and weight. The weight of the hydroxyapatite pallet formed by the tablet punching machine was $0.8 \mathrm{~g}$. The phase composition of prepared HAp powders was analyzed by XRD. The molecular bond structure and 
chemical nature of the synthesized HAp powder were determined using FT-IR. The surface morphology was studied using a scanning electron microscope (SEM).

\section{Preparation of synthetic body fluid (SBF)}

The essential components of SBF are

Merck grade, Sodium Bicarbonate $\left(\mathrm{NaHCO}_{3}\right)$ (99.5\%), Sodium chloride ( $\mathrm{NaCl})$ (99.5\%), Calcium chloride $\left(\mathrm{CaCl}_{2} \cdot \mathrm{H}_{2} \mathrm{O}\right)$ (99.0\%), Potassium chloride $(\mathrm{KCl})(99.0 \%)$, Disodium hydrogen phosphate dihydrate $\left(\mathrm{Na}_{2} \mathrm{HPO}_{4} \cdot 2 \mathrm{H}_{2} \mathrm{O}\right)$ (99.5\%), Disodium sulfate $\left(\mathrm{Na}_{2} \mathrm{SO}_{4}\right)$, Tris(hydroxymethyl)aminomethane $\quad\left(\mathrm{CH}_{2} \mathrm{OH}\right)_{3} \mathrm{CNH}_{2} \quad(99.5 \%)$, Magnesium chloride $\left(\mathrm{MgCl}_{2}\right) .6 \mathrm{H}_{2} \mathrm{O}(99.0 \%)$, and hydrogen chloride (HCL) were used in the preparation of SBF [7].

SBF is a metastable buffer solution [8] and was prepared by adding requisite quantities of the above-mentioned chemicals in distilled water. About $700 \mathrm{ml}$ of distilled water was taken, and each reagent was dissolved one by one. The $\mathrm{pH}$ of the solution was adjusted by the addition of a total of $40 \mathrm{ml}$ of $1 \mathrm{M} \mathrm{HCL}$. To remove turbidity just before the addition of $\left(\mathrm{CaCl}_{2}\right) \cdot 2 \mathrm{H}_{2} \mathrm{O}$, about $15 \mathrm{ml}$ of $1 \mathrm{M} \mathrm{HCL}$ solution was added while the remaining part of the solution was used during subsequent titration. The temperature of the solution was raised from ambient to $37^{\circ} \mathrm{C}$ with the addition of eighth reagent (tris(hydroxymethyl) aminomethane), and then it was followed with titration by $1 \mathrm{M} \mathrm{HCl}$ to a $\mathrm{pH}$ of 7.4 at $37^{\circ} \mathrm{C}$. During the titration process, proper care was taken, and the final volume of the solution was raised to $1 \mathrm{~L}$ with the additions of de-ionized water. It was confirmed from other study that the prepared SBF solutions can be stored at $4^{\circ} \mathrm{C}$ for a month without degradation [9].

\section{Biodegradation test}

The in vitro degradability of the prepared HAp was determined by their weight loss percentage in a $0.05 \mathrm{M}$ Tris-HCL buffer solution. The $\mathrm{pH}$ of the solution was maintained at 7.4 by adding $1 \mathrm{M} \mathrm{HCl}$ at $37^{\circ} \mathrm{C}$. Before weighing of the sample, they were taken out, rinsed with deionized water and dried in an oven at $150^{\circ} \mathrm{C}$. Calcined hydroxyapatite pellets were immersed in tris- $\mathrm{HCl}$ buffer solution for 1 week, and then they were dried at $100^{\circ} \mathrm{C}$. The final weight loss of calcined Hap was determined by the formulae:

$\%$ Weight loss $=(W 1-W 2) / \mathrm{W} 2 \times 100$

Where $W 1$ is the initial weight of sample and $W 2$ the final weight of sample after soaking in Tris- $\mathrm{HCl}$ solution.

\section{FTIR analysis of HAp}

FTIR spectroscopy provides fingerprint information on the chemical composition of the HAp. In FTIR, study interaction between matter and electromagnetic field in the IR region is done. In the spectral region electromagnetic waves couples mainly with the molecular vibration.

FTIR analysis of Hap sample was done by FTIR-8400, Shimadzu. The FTIR spectra of the sample were obtained by the $\mathrm{KBr}$ pellet method using an FTIR spectrophotometer. All of the spectra were collected in the $400-4000 / \mathrm{cm}$ wavenumber range. Infrared spectroscopy was used to characterize intermolecular between components in the system.

\section{XRD analysis of HAp}

XRD technique is used for characterization and identification of compounds based on their diffraction pattern. The phase purity and the levels of crystallinity of the calcined HAp powders were studied by an XRD (PW-1830, Philips, Netherlands) using $\mathrm{Cu}$-K $\alpha$ radiation. XRD is used to measure the average spacing between layers or rows of atoms.

\section{RESULTS AND DISCUSSIONS}

Out of the three different methods used, sonication with magnetic stirring method was the most preferred method for the synthesis of nano hydroxyapatite. This precipitation reaction for the synthesis of HAp uses calcium nitrate and potassium dihydrogen phosphate as starting materials of this reaction. The only byproduct of this reaction was water, and the reaction involved no foreign elements [7].

\section{FTIR analysis of HAp}

Fig 1 shows the FT-IR spectra of HAp. The characteristic bands exhibited in the sample spectra are given here. The FTIR spectrum shows the wave numbers in the FT-IR spectra of chemical groups belonging to precipitated HAp samples. The characteristic band observed at $622 / \mathrm{cm}$ due to the liberation mode of hydrogen-bonded $\mathrm{OH}^{-}$ions liberation band. For hydroxyapatite bands observed at 1031,563,601/cm correspond to $\mathrm{PO}_{4}{ }_{4}^{3-}$ groups $[6,7]$. A broad hydrated $\mathrm{OH}$ peak $(3462 / \mathrm{cm})$ that sourced by $\mathrm{H}_{2} \mathrm{O}$ absorbed from media by stirring techniques can be seen in figure. In addition, some carbonate content was also seen around $1600 / \mathrm{cm}$ which an indication of the presence of carbonate apatite, it might have originated through the absorption of $\mathrm{CO}_{2}$ from the atmosphere [10]. Here, $\mathrm{PO}_{4}{ }^{3-}$ and $\mathrm{HPO}_{4}{ }^{2-}$ indicate the presence of $\mathrm{HAp}$ in the powder [11]. As a result of the FTIR spectrum of the sample, it is obvious that the synthesized powder is certainly hydroxyapatite.

\section{XRD analysis of HAp}

Characterization of the HAp was done with XRD using the XRD. The precipitated powder obtained using double step stirring technique indicates the presence of crystal structure consisting of HAp phases, as is indicated by the XRD pattern as depicted in Fig. 2a. A typical XRD profile of double step stirring method has been shown in Fig. 2b. The appearance of calcined HAp was soft, porous, and white in color. XRD patterns show the formation of HAp, and it resembles well with the standard file [6]. The calcined HAp exhibits crystallized sharp peaks. The HAp powders synthesized from calcium nitrate and potassium dihydrogen orthophosphate are very pure and white in nature, and the peaks resemble JCPDS-090432.

When the magnetic and ultrasonic stirring techniques were used together, the XRD spectrum of the powder obtained by sonication and magnetic stirring method included only HAp phase as shown in Fig. $2 \mathrm{~b}$, it did not contain any unindexed materials. The XRD pattern of the precipitated powder obtained using magnetic stirring technique and ultrasonic stirring technique indicates that the precipitated particles have unindexed peaks in the crystal as these results were attributed to especially weak stirring effect as shown in Fig. 2a which shows the XRD pattern of HAp prepared by the magnetic stirring method. However, the XRD spectrum of the powder obtained using magnetic and ultrasonic stirring techniques together included only hydroxyapatite phase. XRD patterns of the double-step stirring hydroxyapatite sample exhibited crystalline structure, because the crystalline structure has narrower peaks in XRD spectrum.

\section{Bioactive evaluation of HAp by in vitro method}

The in vitro bioactivity of synthesized HAp powder was performed in a SBF media of $\mathrm{pH} 74$ in a water bath at $37^{\circ} \mathrm{C}$. The increase in the $\mathrm{pH}$ of SBF medium from 7.4 to 8.2 was measured at predetermined time intervals using a $\mathrm{pH}$ meter.

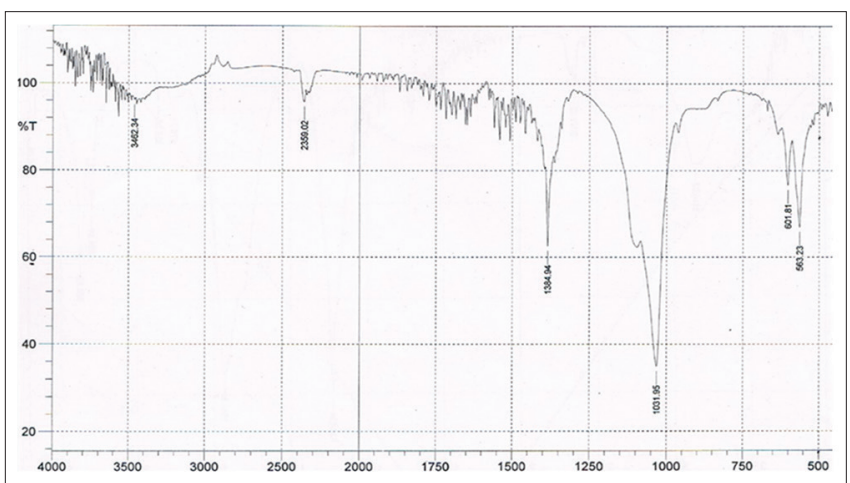

Fig. 1: Fourier transform-infrared spectrum of hydroxyapatite 


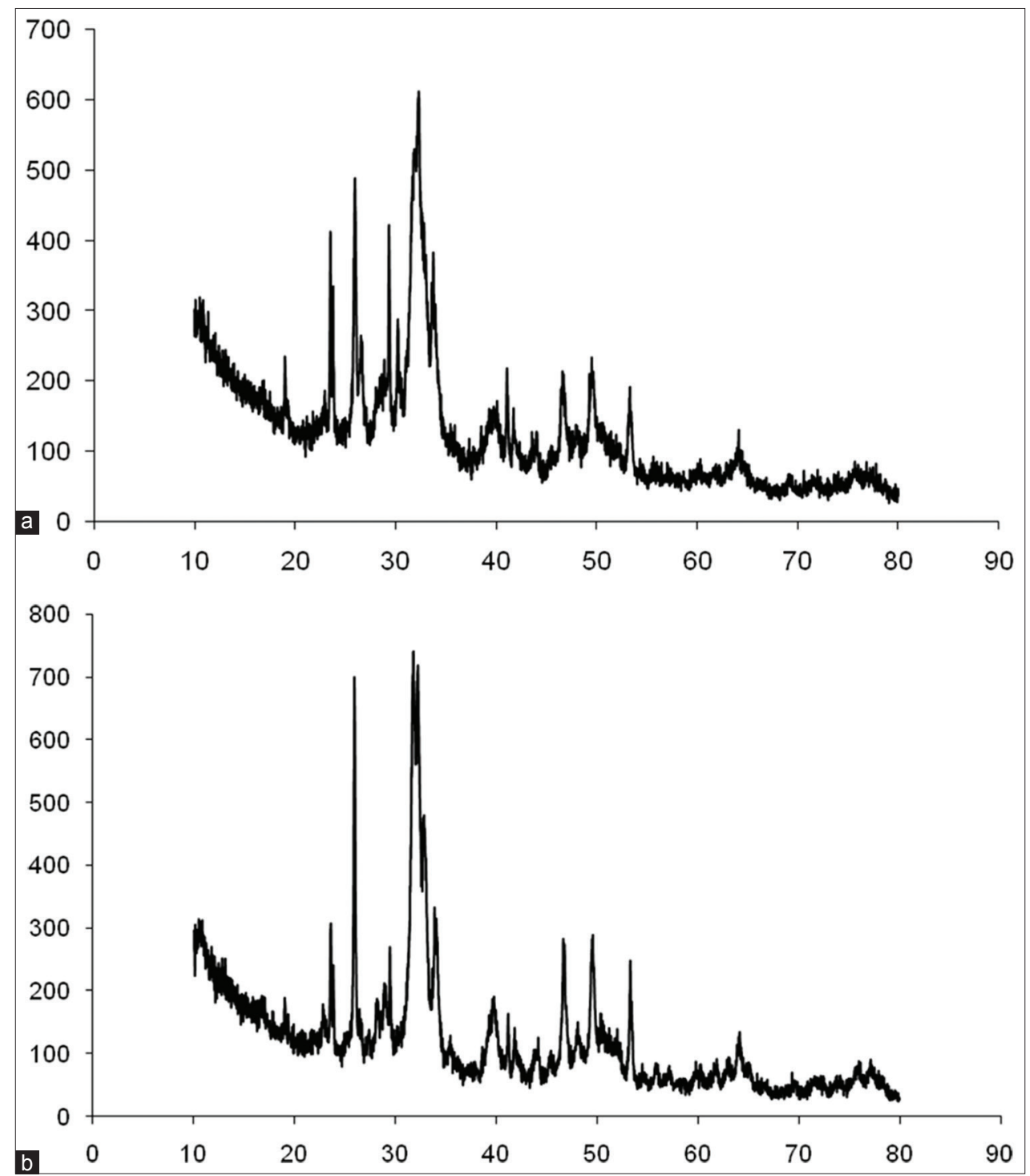

Fig. 2: (a) X-ray diffraction patterns of HAp powders prepared by magnetic stirring method. (b): X-ray diffraction patterns of HA powders prepared by double-step stirring method

Ion exchange pellets are then immersed in freshly prepared SBF for variable duration 3 and 7 days. After a particular incubation duration, 3 and 7 days, the pellets are taken out of SBF solution and were rinsed in deionized water. Later, it was then dried at room temperature and was characterized by SEM.

During the incubation period of HAp, an appetite layer formation occurs on the surface of HAp sample. The layer of apatite formation on the HAp surface is due to the electrostatic interaction of calcium ions and phosphate ions present in SBF. Figs. $3 \mathrm{~b}$ and $\mathrm{c}$ describe bone-like apatite formation on HAp in SBF which can be explained as follows:

There is the formation of two regions, one as Ca-rich ACP (Calcium rich Active calcium phosphate) and Ca-poor ACP (Calcium poor Active calcium phosphate) leading to the formation of apatite on the surface of Hap [12]. On the surface of HAp after being soaked in SBF, it acquires a negative charge by exposing phosphate ions and hydroxyl on the surface of HAp. Due to the presence of negative charge on the surface of Hap, the positively charged calcium ions present in SBF interacts and form a large number of Ca-rich ACP on the surface of Hap. Again, the positively charged Ca-rich ACP will interact with negatively charged phosphate ions present in SBF to form Ca-poor ACP. As a result of which, the formation of apatite will take place on the surface of HAp [13]. This formation of an apatite layer on the surface of Hap was confirmed through SEM analysis.

\section{Biodegradation test of HAp}

Biodegradation behavior of Hap synthesized by chemical precipitation technique and calcined at $800^{\circ} \mathrm{C}$ in the form of pellets was carried out in Tris- $\mathrm{HCl}$ solution. The calcined HAp samples were placed in Trisbuffer solution at $\mathrm{pH} 7.4$ and a temperature of $37^{\circ} \mathrm{C}$ for 7 days. It was observed after some days that there was biodegradation of calcined Hap which resulted in the loss of calcium ion and increase in $\mathrm{pH}$ of the buffer from 7.4 to 8.4. The average weight loss of calcined HAp after 4,8 , and 20 days was $4.16 \%, 4.34 \%$, and $7.05 \%$. The above analysis clearly reveals that HAp has the property of degradation behavior which confirms its bioactive properties.

\section{Bioactivity of hydroxyapatite}

The bioactivity of hydroxyapatite was investigated using the interaction between peripheral blood mononuclear cells and implanted hydroxyapatite material. Hydroxyapatite shows significant potential to be used as an orthopedic implant because it elicits a favorable biological response and forms a bond with the surrounding tissues [14].

In Fig 4, hydroxyapatite was inoculated in cell culture broth, in T flask to observe the bioactivity behavior of hydroxyapatite. The color of cell culture broth before the inoculation of hydroxyapatite was dark blue. As the hydroxyapatite was inoculated in cell culture, broth color of the broth changes to orange after $24 \mathrm{~h}$ of incubation 


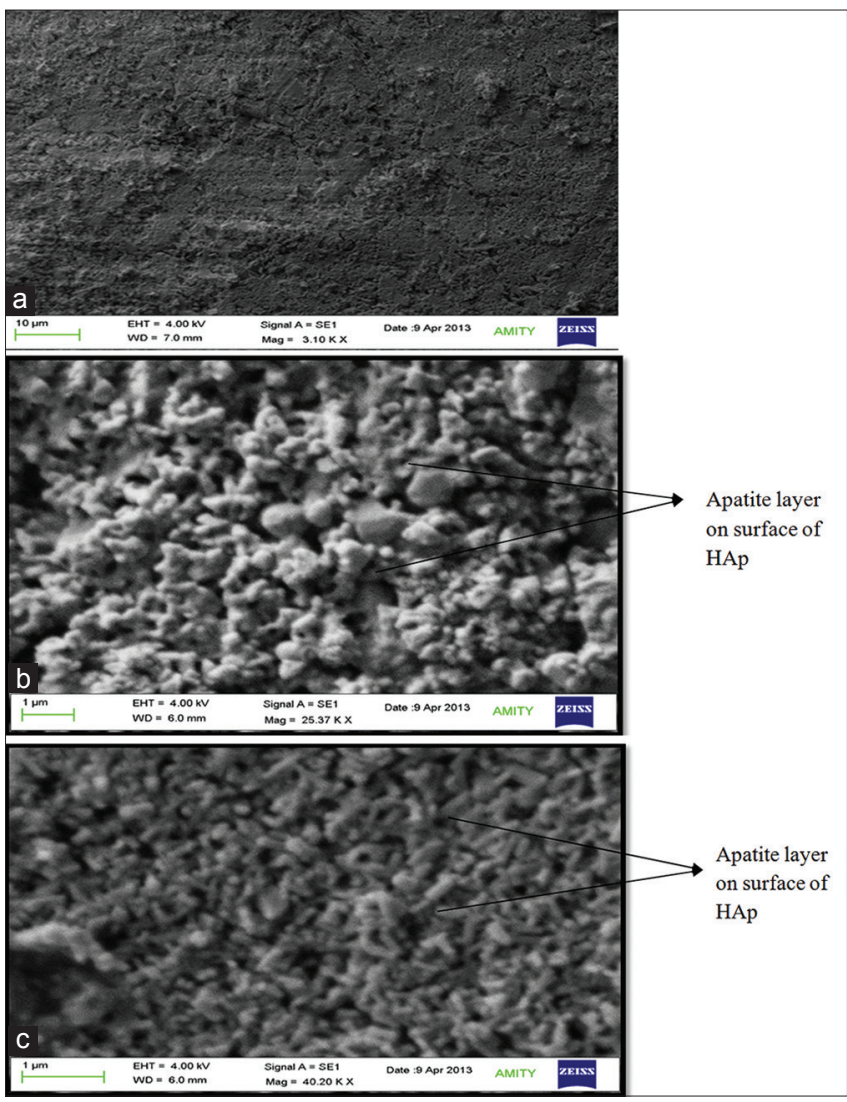

Fig. 3: (a) Scanning electron microscope image of control sample of hydroxyapatite. (b): Scanning electron microscope image

of HAp sample immersed in $\mathbf{3}$ days in synthetic body fluid. (c):

Scanning electron microscope image of HAp sample immersed in 7 days in synthetic body fluid

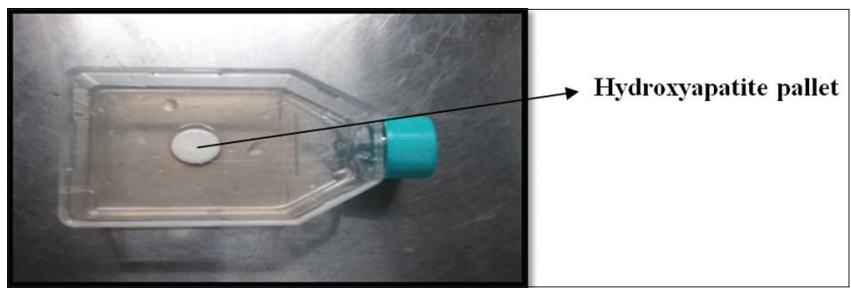

Fig. 4: HAp inoculated in cell culture broth

period demonstrated the growth of the cells. The cell density was calculated before the inoculation of nano hydroxyapatite. After $24 \mathrm{~h}$ of inoculation with hydroxyapatite, the cell density was increased; this demonstrated the good bioactivity behavior of hydroxyapatite. Cell count per $\mathrm{ml}$ broth culture over an incubation period of $12 \mathrm{~h}$ in the absence of hydroxyapatite was found to be $6 \times 10^{7}$ whereas cell count per ml broth in the presence of hydroxyapatite was found to be $8 \times 10^{7}$. Hence, hydroxyapatite was found to have a positive effect on cell growth.

These seeding of peripheral blood mononuclear cells (PBMCS) were subcultured and interacted with the hydroxyapatite. Fig. 5a is the SEM image of hydroxyapatite taken as control sample which is not being inoculated with the peripheral blood mononuclear cells showing the clear surface. Fig. $5 \mathrm{~b}$ is the SEM image of hydroxyapatite inoculated with peripheral blood mononuclear cells. Here, on the surface of the hydroxyapatite growth of the PBMCS was reported. This confirms the bioactivity behavior of hydroxyapatite, and hence hydroxyapatite was found to have a positive effect on cell growth.
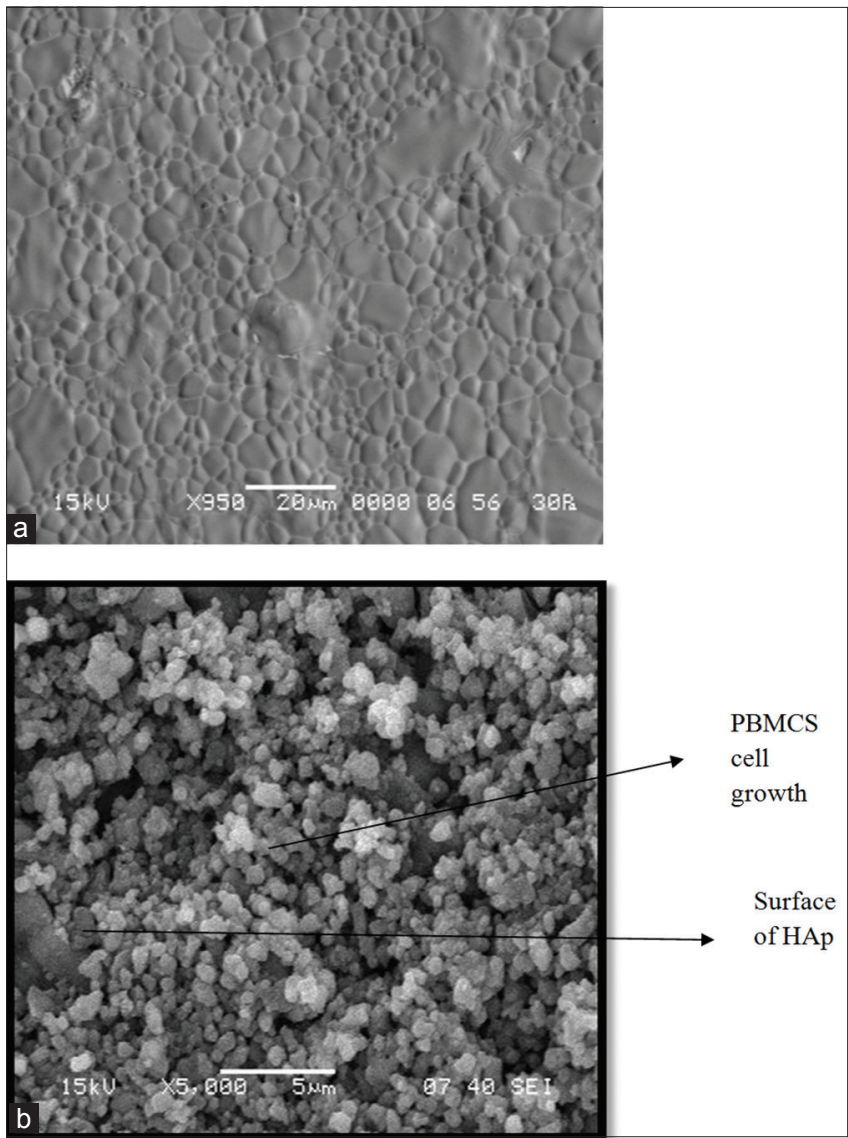

Fig. 5: (a) Seeding of peripheral blood mononuclear cells on to HAp surface: Scanning electron microscope image of HAp taken as control sample. (b): Seeding of peripheral blood mononuclear cells (PBMCS) on to HAp surface: Scanning electron microscope image of HAp showing growth of PBMCS

\section{CONCLUSIONS}

In this study, the chemical precipitation technique could be the optimized process to induce the formation of hydroxyapatite rather than tricalcium phosphate. Pure and thermally stable hydroxyapatite powder was synthesized from the double-step stirring method. HAp obtained from sonication, and magnetic stirring method was not pure. However, the hydroxyapatite powder prepared from doublestep stirring method (sonication + magnetic stirring method) was pure and did not decompose to other phase at high temperature. The synthesized HAp powder has been characterized on a macroscopic level by XRD, FTIR, and SEM, while SEM has provided detailed information at the microscopic level. Bioactivity of the hydroxyapatite is tested by its interaction with SBF and using the Tris-HCL for checking its biodegradation behavior. Furthermore, hydroxyapatite bioactivity was shown by its interaction with the peripheral blood mononuclear cells. The growth of peripheral blood mononuclear cells on the surface of hydroxyapatite was observed from SEM analysis. Furthermore, its biocompatibility was proved by the increase in cell density count in the hemocytometer chamber. Hydroxyapatite can be a better choice of biomaterial used in the implant as orthopedic devices in the coming future. A lot of research and study has to be done on this biomaterial device so that we can improve the mechanical behavior of the HAp and can extensively use to sustain and live a longer life.

\section{AUTHOR'S CONTRIBUTION}

Ishfaq Rasool has contributed in executing and writing the research work and adjuvant sigh in conceptualization and editing the manuscript. 


\section{CONFLICTS OF INTEREST}

There are no conflicts of interest declared among the authors.

\section{REFERENCES}

1. Murugan R, Ramakrishna S. Porous bovine hydroxyapatite for drug delivery. J Appl Biomater Biomech 2005;3:93-7.

2. Mogh T, Mangesh G, Pratima A. A brief review: Biomaterials and their application. Int J Pharm Pharm Sci 2010;2:19-23.

3. Rani KC, Primaharinastiti R, Hendradi E. Preparation and evaluation of ciprofloxacin implants using bovine hydroxyapatite-chitosan composite and glutaraldehyde for osteomyelitis. Int J Pharm Pharm Sci 2015;8:45-51.

4. Chaudhry A, Haque S, Kellici S, Boldrin P, Rehman I, Fazal A, et al. Instant nano-hydroxyapatite: A continuous and rapid hydrothermal synthesis. R Soc Chem 2006;21:2286-8.

5. Jarcho M. Retrospective analysis of hydroxyapatite development for oral implant applications. Dent Clin North Am 1992;36:19-26.

6. Binnaz H, Yoruc A, Yeliz K. Double step stirring: A novel method for precipitation of nano-sized hydroxyapatite powder. Dig J Nanomater Biostruct 2009;4:73-81.
7. Bayraktar D, Tas AC. Chemical preparation of carbonated calcium hydroxyapatite powders at $37^{\circ} \mathrm{c}$ in urea-containing synthetic body fluids. J Eur Ceram Soc 1999;19:2573-9.

8. Li P, Nakanishi K, Kokubo T, de Groot K. Induction and morphology of hydroxyapatite, precipitated from metastable simulated body fluids on sol-gel prepared silica. Biomaterials 1993;14:963-8

9. Tas AC. Synthesis of biomimetic ca-hydroxyapatite powders at 37 degrees C in synthetic body fluids. Biomaterials 2000;21:1429-38.

10. Chaudhry AA, Haque S, Kellici S, Boldrin P, Rehman I, Khalid FA, et al. Instant nano-hydroxyapatite: A continuous and rapid hydrothermal synthesis. Chem Commun 2006;21:2197-296.

11. Sopyan L, Singh R, Hamdi MM. Synthesis of nano sized hydroxyapatite powder using sol-gel technique and its conversion to dense and porous bodies. Indian J Chem 2008;47A:1626-31.

12. Singh A. Hydroxyapatite, a biomaterial: Its chemical synthesis, characterization and study of biocompatibility prepared from shell of garden snail Helix aspersa. Bull Mater Sci 2012;35:1031-8.

13. Williamson GK, Hall WH. X-ray line broadening from filed aluminum and wolfram. Acta Metall 1953;1:22-31.

14. Nery EB, LeGeros RZ, Lynch KL, Lee K. Tissue response to biphasic calcium phosphate ceramic with different ratios of HA/beta TCP in periodontal osseous defects. J Periodontol 1992;63:729-35. 